\section{Pessoas vivendo com HIV/AIDS: variáveis associadas à adesão ao tratamento anti-retroviral}

\author{
Persons living with HIV/AIDS: factors \\ associated with adherence to antiretroviral \\ treatment
}

${ }_{1}^{1}$ Instituto de Psicologia, Universidade de Brasília, Brasília, Brasil.

Correspondência E. M. F. Seidl Instituto de Psicologia, Universidade de Brasília. Campus Darcy Ribeiro, Brasília, $D F$ 70910-900, Brasil. seidl@unb.br

\begin{abstract}
This study aimed to describe the adherence of persons living with HIVIAIDS to antiretroviral therapy (ART) and to investigate adherence predictors among the following: level of schooling, presence of side effects, current or previous interruption of ART by the persons themselves, self-esteem, self-efficacy expectation, coping strategies, social support, and satisfaction with the health professional-patient relationship. Adherence was measured by self-reported number of ART pills/ capsules missed during the previous week and previous month, evaluated as satisfactory when less than 5\%. $101 \mathrm{HIV}+$ adults took part in this study, $60.4 \%$ males, ranging from 20 to 71 years of age (mean $=37.9$ years), and $73.3 \%$ symptomatic. Data procedures included interviews and the use of validated instruments. The majority of participants ( $n=73 ; 72.3 \%$ ) reported adherence of $\geq 95 \%$. Logistic regression showed that a history of self-reported ART interruption and self-efficacy expectations were significant adherence predictors. Upgrading of care with interdisciplinary teams is needed to develop an appropriate approach to the medical and psychosocial difficulties of ART adherence by persons with HIVIAIDS.
\end{abstract}

Highly Active Antiretroviral Therapy; Acquired Immunodeficiency Syndrome; HIV
Eliane Maria Fleury Seidl 1

Adriana Melchíades 1

Vivyanne Farias 1

Alexander Brito 1

\section{Introdução}

Desde meados dos anos 80, medicamentos anti-retrovirais (ARV) têm sido utilizados no tratamento da Síndrome da Imunodeficiência Adquirida (AIDS). Os primeiros anti-retrovirais permitiam benefícios temporários, em razão da baixa eficácia na recuperação da capacidade imunológica e os efeitos limitados sobre a redução da carga viral. A partir de 1996, com o advento de novas classes de ARV - inibidores da protease e os inibidores de transcriptase reversa não nucleosídios - foi possível alcançar, mediante a terapia anti-retroviral combinada (Highly Active Antiretroviral Therapy - HAART), êxitos significativos no tratamento de pessoas infectadas pelo HIV. Constatou-se, em decorrência, a diminuição relevante nos índices de morbidade e mortalidade por AIDS 1,2,3.

Aolado da disponibilidade desses recursos terapêuticos e do otimismo quanto ao prognóstico em HIV/AIDS, constata-se que alguns pacientes não têm usufruído as vantagens do tratamento. Isso porque um aspecto é crucial para o sucesso da terapia anti-retroviral (TARV): a adesão ao tratamento, definida como "compromisso de colaboração ativa e intencionada do paciente, com a finalidade de produzir um resultado preventivo ou terapêutico desejado" 4 (p. 232). Nessa perspectiva, a aquisição e manutenção da conduta de adesão ao tratamento são fundamentais para a obtenção de bons resultados terapêuticos. 
Pesquisas mostram que mesmo falhas ocasionais na adesão à TARV podem limitar os benefícios do tratamento. Paterson et al. 5 reportaram que $81 \%$ dos pacientes com $95 \%$ ou mais de adesão obtiveram níveis de carga viral abaixo de 400 cópias/ml, em uso de esquemas que incluíam inibidores de protease. Entre os pacientes com $80 \%$ a $90 \%$ de adesão, apenas a metade obteve redução satisfatória da carga viral. Estudos reforçam esses achados ao concluir que os efeitos máximos desejados do tratamento anti-retroviral são obtidos quando se alcança, no mínimo, 95\% de adesão às doses prescritas 6 .

As dificuldades de adesão em HIV/AIDS decorrem, em parte, da complexidade da TARV, na medida em que alguns medicamentos precisam ser ingeridos com alimentos, outros em jejum, ou em seqüências temporais combinadas com outros medicamentos, o que exige organização e compromisso do paciente em relação ao seu tratamento. Outra barreira importante refere-se à presença de efeitos colaterais 1 . Nestes casos, tomar a medicação pode representar uma situação aversiva por causa da ocorrência de conseqüências adversas e desconfortáveis. A ocorrência de lipodistrofia, por exemplo, constitui-se em grande desafio, tanto para as pessoas HIV+ quanto para as equipes de saúde 7 .

Ao lado dos fatores de natureza biomédica que influenciam os níveis de adesão e os resultados da TARV, aspectos psicossociais suscitam o interesse de pesquisadores e profissionais de saúde. Duas variáveis investigadas têm sido o suporte social e o enfrentamento (coping). Sing et al. 8 observaram que a satisfação com o suporte social e a utilização de estratégias de enfrentamento comportamentais ativas estiveram associadas à adesão em amostra de pacientes $\mathrm{HIV}+$. Os pesquisadores verificaram ainda que a não-adesão esteve relacionada a sentimentos de desesperança e a estratégias de enfrentamento de esquiva. O suporte social foi apontado por sua influência tanto direta - disponibilização de encorajamento e motivação para o autocuidado -, quanto indireta, ao atenuar os efeitos de situações que interferiam negativamente sobre a adesão.

A expectativa de auto-eficácia também tem recebido a atenção de pesquisadores interessados na adesão ao tratamento em HIV/AIDS 9. Bandura 10,11 define auto-eficácia como a crença da pessoa em sua capacidade para organizar e executar as ações requeridas para produzir determinado resultado. Nessa concepção teórica, o indivíduo é visto como capaz de lidar ou manejar as circunstâncias que eventualmente o impeçam de realizar comportamentos de saúde, tanto preventivos quanto de tratamento. Em estudos com amostras de pessoas vivendo com HIV/AIDS, escores mais elevados em expectativa de autoeficácia estiveram associados à melhor adesão à TARV 12,13 .

Outra variável de interesse em pesquisas no campo da psicologia da saúde é a auto-estima, componente da personalidade que se caracteriza pela avaliação que a pessoa faz de si mesma. Sentimentos de menos-valia poderiam favorecer a negligência nos cuidados de saúde, enquanto auto-estima elevada poderia levar a crenças de invulnerabilidade pelo fato de a pessoa possuir sentimentos excessivamente positivos sobre si mesmo (Leary, 1999, apud Gonçalves 14).

A associação entre variáveis sócio-demográficas - gênero, idade, etnia, escolaridade e renda - e adesão à TARV tem sido pesquisada com resultados controversos 15. Estudo com pessoas HIV+ brasileiras constatou que, entre variáveis sócio-demográficas e clínicas, apenas escolaridade apresentou associação significativa com adesão, sendo esta mais satisfatória entre pessoas com mais anos de estudo 13 .

A qualidade da interação profissional de saúde-usuário pode ser definida como a capacidade de se criar uma relação de cooperação entre ambos. Programas que favorecem o estabelecimento da vinculação entre profissionais de saúde e usuários dos serviços têm melhores níveis de adesão ao tratamento, segundo estudos com outras clientelas 16 . Paiva et al. 17 destacaram que a complexidade da adesão aos ARV decorre das modificações na vida cotidiana pelo uso diário dos medicamentos. Os autores apontaram que os efeitos colaterais (náuseas, enjôos, mal-estar), bem como as dificuldades de comunicação entre pacientes e profissionais de saúde são de grande relevância na adesão. Em HIV/AIDS, a relação com o usuário deve caracterizar-se por uma postura de acolhimento, para o atendimento de demandas específicas e sua participação no planejamento e decisão acerca do seu próprio tratamento.

Carvalho et al. 18, pesquisando a adesão à TARV em residentes no Distrito Federal, Brasil, constataram que $76 \%$ dos pacientes pesquisados relataram níveis de adesão iguais ou superiores a 95\%, e renda familiar inferior a três salários-mínimos e uso de drogas ilícitas foram as variáveis significativas que constituíram maiores chances de adesão insatisfatória. Estudo realizado por Seidl 19, com 241 pacientes HIV+ do Distrito Federal, constatou que $38,8 \%$ referiram interrupção do tratamento com anti-retrovirais por conta própria, em algum momento da história da enfermidade, e os principais motivos mencionados foram presença de efeitos colaterais e razões de natureza subjetiva e/ou psicológica. Outro estu- 
do brasileiro verificou que os mais fortes preditores da não-adesão foram presença de depressão e suporte social insatisfatório 20 . O autor observou $31 \%$ de não-adesão na amostra pesquisada.

Um desafio que permeia os estudos sobre adesão em enfermidades crônicas é a sua avaliação. O auto-relato tem sido uma fonte de informação muito usada para identificação da conduta de adesão, pela acessibilidade e praticidade 21,22 . No entanto, o auto-relato tem aspectos limitadores como a memória, o nível sócio-cultural e o relacionamento com a equipe de saúde, que podem influenciar a veracidade dos relatos dos pacientes.

Dez anos de experiência no atendimento psicossocial a pessoas soropositivas no Hospital Universitário de Brasília têm mostrado que a adesão em HIV/AIDS se constitui em grande desafio para os profissionais de saúde. Pesquisas que permitam uma melhor compreensão do fenômeno, investigando a influência de variáveis sócio-demográficas, clínicas e psicossociais, são fundamentais para o desenvolvimento de estratégias de intervenção que favoreçam a adesão à TARV.

O presente estudo teve como objetivos: (1) descrever o comportamento de adesão ao tratamento anti-retroviral de pessoas vivendo com HIV/AIDS; (2) investigar fatores preditores da adesão à terapia anti-retroviral, considerando variáveis sócio-demográficas (escolaridade), clínicas (presença de efeitos colaterais e interrupção anterior da TARV por conta própria) e psicossociais (auto-estima, expectativa de auto-eficácia, estratégias de enfrentamento, suporte social e satisfação com a relação profissional de saúdeusuário). A escolha das variáveis preditoras decorreu da revisão da literatura sobre o tema, bem como da experiência clínica dos pesquisadores no atendimento à clientela específica. A variável adesão foi medida por meio do auto-relato da perda do número de comprimidos/cápsulas dos medicamentos anti-retrovirais na última semana e/ou no último mês. A adesão foi avaliada como satisfatória na ocorrência de ingestão de comprimidos/cápsulas igual ou superior a $95 \%$ no período indicado 5,6 .

\section{Metodologia}

O estudo teve delineamento de corte transversal, com amostra de conveniência composta de 101 pessoas HIV+ que faziam seu tratamento em dois serviços especializados em HIV/AIDS da rede pública de saúde do Distrito Federal. Tais serviços somavam aproximadamente 1.300 pacientes cadastrados no período da coleta de dados (mar- ço a setembro de 2004). O critério de inclusão dos participantes foi fazer uso da TARV há, no mínimo, seis meses, com qualquer esquema de medicamentos ARV. Como critério de exclusão, foi considerado o nível de escolaridade inferior a três anos de estudo, tendo em vista a utilização de instrumentos auto-aplicáveis na coleta de dados, adequados aos objetivos e ao desenho da pesquisa. Foi ponderado, ademais, que esse critério não teria impacto importante na exclusão de participantes tendo em vista a existência de número reduzido de pacientes que não apresentava esse nível de escolarização nos dois serviços pesquisados, estimado em menos de $5 \%$ da clientela cadastrada.

\section{Procedimentos}

Após aprovação do Comitê de Ética em Pesquisa, a coleta de dados teve início com os pacientes, sendo convidados a participar quando compareciam ao serviço de saúde em dias de consulta médica ou para procedimentos diversos (exames laboratoriais, buscar medicação anti-retroviral na farmácia). Apenas as pessoas que concordaram com os Termos do Consentimento Livre $e$ Esclarecido - e assinaram as duas vias do documento - foram incluídas no estudo. O percentual de recusas foi da ordem de $10 \%$.

Acoletadedadosobedeceuàseguinteseqüência quanto à apresentação dos instrumentos: questionários sobre aspectos sócio-demográficos e clínicos (aplicados mediante entrevista), seguidos dos instrumentos (escalas) auto-aplicados. O pesquisador esteve próximo ao paciente durante a resposta às escalas, fornecendo orientações para o preenchimento, esclarecendo dúvidas e evitando a ocorrência de dados perdidos. O tempo médio da coleta de dados foi de 60 minutos.

Para obtenção dos dados sobre contagem dos linfócitos T CD4 e da carga viral plasmática, os prontuários foram consultados e identificados os exames realizados em data a mais próxima à participação na pesquisa, em períodos que variaram de seis meses antes até seis meses depois da coleta. Reitera-se que os dados sobre CD4 e carga viral foram utilizados apenas na descrição da amostra quanto aos indicadores imunológicos e virológicos.

Estudos dessa natureza permitem a identificação de demandas de atendimento durante a coleta de dados. Foi garantida a disponibilização de informações, orientação e/ou aconselhamento, bem como o encaminhamento do paciente para atendimento específico (médico e/ou psicossocial), quando necessário, em especial os que apresentavam problemas de adesão. 


\section{Instrumentos}

\section{- Questionários sócio-demográfico e clínico}

Roteiros estruturados de entrevista. O clínico incluiu perguntas (fechadas e abertas) como tempo de diagnóstico de retrovirose, condição clínica auto-relatada (sintomática versus assintomática), tempo de uso da TARV, interrupção anterior da TARV por conta própria, percepção de dificuldade de uso dos ARV, percepção sobre as condições atuais de saúde e benefícios da TARV, satisfação com a relação profissional de saúde-usuário (três questões que investigaram a satisfação com o atendimento médico e dos demais profissionais de saúde, com respostas em escala Likert de 5 pontos e escores obtidos pela média aritmética, variando de um a cinco, alpha de Cronbach igual a 0,71).

A informação sobre a variável adesão ao tratamento foi obtida por auto-relato referente ao esquema atual da TARV (nomes dos medicamentos, quantidade de cápsulas/comprimidos diários de cada medicação e horários), dados que foram colhidos com o auxílio de uma tabela para auxiliar o paciente a recordar e informar sobre seu esquema terapêutico. Era solicitado, então, que o participante estimasse quantos comprimidos/cápsulas dos ARV teria deixado de tomar na semana e no mês anterior, o que permitiu o cálculo do percentual de comprimidos/cápsulas perdidos na última semana e no último mês, computado com base no número total que deveria ter sido tomado. O paciente também foi incluído no grupo de pessoas com adesão insatisfatória se a perda de comprimidos/cápsulas superior a 5\% tivesse ocorrido em apenas uma das condições (na semana ou no mês), visando apreender melhor a ocorrência de dificuldades de adesão, em duas perspectivas temporais. Relatos sobre atrasos nos horários de uso da medicação foram obtidos e descritos, mas não foram utilizados na análise multivariada, tendo em vista que o critério usado para definir o tipo de adesão foi a ingestão (ou não) do medicamento, independente do atraso ocorrido.

\section{- Escala modos de enfrentamento de problemas (EMEP)}

Instrumento oriundo da análise fatorial de Seidl et al. 23 para avaliação dos modos de enfrentamento em relação à soropositividade, definidos como estratégias cognitivas e/ou comportamentais voltadas para o manejo de estressores específicos, que são avaliados como sobrecarga aos recursos da pessoa. É composta de 45 itens em quatro fatores: (1) enfrentamento focalizado no problema (18 itens; $\alpha=0,84$ ) - estratégias comportamentais de aproximação em relação ao estressor, voltadas para o seu manejo ou solução, bem como estratégias cognitivas direcionadas para a reavaliação e ressignificação do problema; (2) enfrentamento focalizado na emoção (15 itens; $\alpha=0,81$ ) - estratégias cognitivas e comportamentais de esquiva e/ou negação, expressão de emoções negativas, autoculpa e/ou culpabilização de outros, com função paliativa ou de afastamento do problema; (3) busca de práticas religiosas/pensamento fantasioso (5 itens; $\alpha=0,74)$ - pensamentos e comportamentos religiosos e/ou fantasiosos como modos de enfrentamento e manejo do estressor; (4) busca de suporte social ( 7 itens; $\alpha=0,70$ ) - procura de apoio social emocional e/ou instrumental para ajudar a lidar com o problema. Os escores, obtidos pela média aritmética, variam de um a cinco para cada fator; os valores mais elevados indicam maior utilização de determinada estratégia de enfrentamento. As respostas foram dadas em escala Likert de 5 pontos ( $1=$ nunca faço isso; $5=$ faço isso sempre). Análise dos indicadores de consistência interna na amostra específica do estudo apontou valores satisfatórios e semelhantes aos do estudo de validação para enfrentamento focalizado no problema $(\alpha=0,83)$ e focalizado na emoção $(\alpha=0,83)$, ao lado de índices mais baixos, porém aceitáveis, para busca de práticas religiosas/pensamento fantasioso $(\alpha=0,64)$ e busca de suporte social $(\alpha=0,60)$.

\section{- Escala de suporte social para pessoas vivendo com HIV/AIDS}

Instrumento cuja estrutura foi analisada por Seidl 19,24, por intermédio da adaptação de um instrumento canadense 25 . O instrumento brasileiro possui dois fatores: Fator 1, suporte social emocional (12 itens; $\alpha=0,92$ ) - percepção e satisfação quanto à disponibilidade de escuta, atenção, informação, estima, companhia e apoio emocional em relação à soropositividade; Fator 2 , suporte social instrumental (10 itens; $\alpha=0,84$ ) - percepção e satisfação quanto à disponibilidade de apoio no manejo ou resolução de questões operacionais do tratamento ou do cuidado de saúde, de atividades práticas do cotidiano, de ajuda material e/ou financeira. A escala de respostas, quanto à disponibilidade e freqüência das duas categorias de suporte, foi Likert de 5 pontos: (1) nunca a (5) sempre, e (1) muito insatisfeito a (5) muito satisfeito, para os itens relativos à satisfação. A escala foi usada de modo unifatorial, em função da existência de um fator de segunda ordem, dada a correlação elevada entre os dois fatores $(r=0,57$; $<<0,001)$. No presente estu- 
do, verificou-se correlação positiva significativa $(\mathrm{r}=0,58 ; \mathrm{p}<0,001)$ entre suporte emocional $\mathrm{e}$ instrumental, fato que fortaleceu a decisão sobre o uso do instrumento em sua versão unifatorial. $\mathrm{O}$ escore variou de 1 a 5 , sendo o $\alpha=0,92$. Escores mais altos refletiram percepção de disponibilidade e maior satisfação com o suporte social recebido.

\section{- Escala de auto-estima}

Desenvolvida por Rosenberg (1965 apud Gonçalves 14). Segundo Gonçalves 14 a escala foi validada por Hutz no Rio Grande do Sul, mas esse estudo não foi publicado. Possui 10 itens e as respostas são dadas em escala Likert com quatro alternativas $(1=$ discordo totalmente a $4=$ concordo totalmente). O escore foi obtido pelo cálculo da média aritmética dos 10 itens, variando de 1 a 4, e escores mais elevados foram indicativos de auto-estima mais elevada. A escala é unifatorial $(\alpha=0,78)$. No presente estudo, o $\alpha=0,73$.

\section{- Escala de auto-eficácia para seguir tratamento anti-retroviral}

Escala desenvolvida por Leite et al. 9, com o objetivo de investigar a expectativa de auto-eficácia em situações que podem dificultar o seguimento das prescrições da TARV, permitindo a identificação das que podem representar riscos de nãoadesão à TARV. É unifatorial com 21 itens $(\alpha=$ $0,96)$ com respostas em escala Likert de cinco pontos $(0=$ com certeza não vou tomar; $4=$ com certeza vou tomar). Os escores variam de 0 a $4 \mathrm{e}$ valores mais altos indicam melhor expectativa de auto-eficácia para adesão à TARV. O valor do $\alpha=$ 0,89 nessa amostra foi muito satisfatório.

\section{Análise de dados}

A análise das questões abertas do questionário clínico incluiu a categorização, identificação de freqüências e seleção de exemplos de relatos mais ilustrativos das categorias por dois pesquisadores independentes (índice de concordância de $80 \%$ no mínimo). O propósito foi descrever e agregar informação qualitativa ao tema do estudo, valendo-se de relatos verbais dos participantes.

Análises estatísticas descritivas das variáveis sócio-demográficas, clínicas e psicossociais foram realizadas. No caso das variáveis contínuas, observaram-se distribuições próximas da normalidade, dadas pelos valores das médias, medianas, desvios-padrão e amplitude. No entanto, as variáveis expectativa de auto-eficácia e satisfação com a relação profissional de saúde-usuário apresentaram assimetria mais acentuada à direita, mas não a ponto de ferir pressupostos de normalidade para análises multivariadas. Não foram encontrados casos extremos e discrepantes (outliers) univariados e multivariados 26 .

Análises estatísticas bivariadas preliminares incluíram teste t de Student e teste qui-quadrado. Antes de proceder à análise multivariada, matrizes de correlação entre as variáveis mostraram a ausência de multicolinearidade. Gráficos da relação entre os valores preditos da variável dependente e os erros de predição (os resíduos), bem como gráficos da distribuição dos resíduos e scatterplots entre as variáveis pesquisadas, permitiram concluir quanto à adequação da normalidade das variáveis. Procedeu-se, então, à regressão logística padrão para identificação dos preditores da adesão ao tratamento anti-retroviral, conforme os procedimentos sugeridos por Tabachnick \& Fidell 26. Os índices Cox-Snell e Nagelkerke foram usados para avaliar o percentual de variância explicada da variável dependente. Considerou-se o valor de $\mathrm{p}<0,05$ como nível de significância. O programa estatístico SPSS versão Windows 11.5 (SPSS Inc., Chicago, Estados Unidos) foi utilizado na análise quantitativa de dados.

\section{Resultados}

\section{Caracterização sócio-demográfica}

Sessenta e um $(60,4 \%)$ participantes eram do sexo masculino, com média de idade de 37,88 anos (DP $=7,48)$, variando de 20 a 71 anos. Grande parte dos participantes tinha nível de escolaridade equivalente ao ensino fundamental incompleto (26,7\%) e completo (19,8\%), e $37,7 \%$ cursaram o ensino médio incompleto e completo. Quanto à situação conjugal, o número de solteiros se igualou aos dos que viviam com cônjuge ou companheiro, atingindo, cada um, 36,7\%. Separados, divorciados ou viúvos totalizaram $24,6 \%$. Cerca de um terço dos pacientes $(31,7 \%)$ não possuía filhos, $21,8 \%$ tinham um filho e $41,5 \%$ possuíam dois ou mais filhos.

Pessoas com atividades ocupacionais autônomas (regulares e eventuais) totalizaram $21,7 \%$, enquanto $17,9 \%$ informaram possuir emprego fixo (a maioria com carteira assinada). O percentual de desempregados se igualou ao de aposentados: $22,8 \%$ em cada uma das categorias. Grande parte dos entrevistados $(57,4 \%)$ possuía renda de menos de um até dois salários mínimos. 


\section{Caracterização clínica}

A grande maioria (92,1\%) dos participantes estava em atendimento ambulatorial; todavia, 7,9\% foram entrevistados quando estavam internados em um dos serviços em que o estudo foi realizado. A maior parte relatou condição sintomática ( $\mathrm{n}=$ $74 ; 73,3 \%)$. Sessenta e um deles $(60,4 \%)$ referiram um ou mais episódios de internação em função do HIV/AIDS ao longo da história da enfermidade, enquanto 40 (39,6\%) negaram episódios de internação. O tempo de diagnóstico variou de menos de um ano a 19 anos $(\mathrm{M}=6,0 ; \mathrm{DP}=4,0)$. $\mathrm{O}$ tempo de uso dos ARV oscilou de seis meses a 15 anos $(\mathrm{M}=4,9 ; \mathrm{DP}=3,22)$.

A contagem dos linfócitos T CD4 apontou a variabilidade desse indicador na amostra, de 10 a 873 células $/ \mathrm{mm}^{3}$ de sangue periférico $(M=295,6$; $\mathrm{DP}=194,3)$. A carga viral plasmática variou de 50 a 410 mil cópias $(\mathrm{M}=18.769,7 ; \mathrm{DP}=58.922,8)$, e 35 participantes $(37,6 \%)$ estavam com carga viral indetectável $(\log =1,9)$, indicador da boa eficácia da TARV.

A maioria dos participantes ( $n=62 ; 62,4 \%$ ) fez uma avaliação positiva de sua condição de saúde naquele momento, descrevendo-a como muito boa ou boa, e 30 (29,7\%) referiram saúde regular. Sobre a percepção quanto ao papel de proteção dos ARV em relação ao agravamento da AIDS, houve variabilidade reduzida entre os participantes: $81,2 \%$ referiram que os ARV protegiam completamente ou muito, indicando que grande parte da amostra estava com percepção positiva sobre esse aspecto dos ARV.

\section{Adesão à terapia anti-retroviral}

Com base no auto-relato sobre o número de comprimidos/cápsulas prescritos em relação ao de comprimidos/cápsulas não ingeridos, a maioria $(\mathrm{n}=73 ; 72,3 \%)$ dos participantes foi classificada no grupo que apresentava nível de adesão igual ou superior a 95\% no último mês e semana e $27,7 \%(n=28)$ foram incluídos no grupo com adesão insuficiente (perda de comprimido superior a $5 \%$ no mês e/ou na semana anterior). Entre os 28 participantes incluídos no grupo de pessoas não aderentes, oito informaram perda de $100 \%$ do total de comprimidos/cápsulas do esquema prescrito, tanto na semana quanto no mês anterior. Observou-se ainda que esses oito casos relataram interrupção anterior da TARV em outro(s) momento(s) da história do tratamento. Quanto a atrasos na ingestão da medicação, 37\% relataram que não atrasavam, $33 \%$ às vezes atrasavam, $14 \%$ atrasavam muitas vezes e $16 \%$ informaram atraso freqüente no uso da medicação. Foi indagado sobre o tempo médio de ocorrência dos atrasos: estes variavam entre 10 a $180 \mathrm{mi}$ nutos, e $50 \%$ informaram atrasos que oscilavam entre 30 e 60 minutos.

A análise do CD4 em três níveis $(\leq 200 ; 201$ a 350 ; $\geq 351$ ) mostrou associação significativa com a variável adesão: número maior de pessoas com adesão satisfatória apresentava CD4 entre 201 e $350(33,8 \%)$ e superior a $350(35,2 \%)$, ao passo que as não aderentes estavam em grande parte $(59,3 \%)$ com CD4 menor que $200\left(\chi^{2}=6,6\right.$; $\mathrm{df}=2 ; \mathrm{p}<0,05)$.

A maioria dos participantes (56,5\%) disse jamais ter interrompido seu tratamento por conta própria desde o início do tratamento com ARV, mas $43,5 \%$ admitiram ter interrompido o uso uma vez ou mais (não foi investigada a duração dos períodos de interrupção). Aqueles que responderam jamais terem interrompido, justificaram a manutenção do uso da medicação pela ausência de efeitos colaterais e inexistência de qualquer motivo para tal. Aqueles que interromperam o uso da medicação referiram presença de efeitos colaterais ("Porque passava muito mal: tontura, nervosismo, enjôo"; "Dores no estômago"), uso de substâncias psicoativas ("Eu bebia muito e fumava muita merda, usava cocaína e o tratamento não combinava com as drogas”), dificuldade de adaptação à rotina do tratamento ("Ficar tomando remédio todos os dias não anima, não. Chega em um ponto que vai cansando"; "Eu cansei de tomar remédios"), presença de sentimentos de desesperança e/ou depressão ("Estava revoltada, triste, não acreditava"; "depressão"), decisão pessoal de interrupção do uso ("Porque eu não quis tomar"), e crenças de invulnerabilidade diante da AIDS ("Achava que a AIDS nunca ia me derrubar"; "Pensei que estava bom").

Investigou-se ainda a presença de efeitos colaterais no momento da coleta: $61,4 \%$ não referiram essa ocorrência e 39,6\% relataram algum tipo de efeito colateral. Dentre os que se queixaram desses efeitos, foram mencionados em maior freqüência sintomas no trato gastrointestinal ("Náuseas e dores no estomago"; "Intoxicação, mal-estar, enjôo e falta de apetite”), lipodistrofia e suas conseqüências ("Aumento da taxa de triglicerídeos", "Lipodistrofia”) e efeitos neurológicos ("Sonolência, calafrios, desmaios").

Sobre a percepção de dificuldades no uso dos ARV, o grupo se distribuiu entre os que não relataram dificuldades $(52,5 \%)$, os que achavam um pouco difícil $(30,7 \%)$ e os que consideravam que era muito difícil (16,8\%). A não dificuldade foi justificada pela ausência de efeitos colaterais, estabelecimento de uma rotina, facilidade de acesso à medicação e número reduzido de doses exigidas ("Tranqüilo, nunca deu efeito colateral"; 
"Já faz parte da minha vida"; "É fácil conseguir o remédio"). Os relatos que apontaram dificuldades se distribuíram em diferentes motivos, incluídos nas seguintes categorias: esquecimento, falta de hábito, presença de efeitos colaterais, problemas sócio-econômicos e excesso de medicamentos ("Às vezes durante o trabalho a gente esquece"; "Porque a pessoa tem que viver só para os remédios, tem que estar tomando tudo na hora certa"; "O organismo não aceita, problemas financeiros, tenho necessidade de boa alimentação devido à reação dos remédios e não tenho dinheiro para comprar"; "Tomar várias medicações todos os dias é terrivel").

Foi investigada ainda a presença de situações atuais na vida da pessoa que estivessem prejudicando a adesão. As categorias identificadas foram: presença de rotinas cotidianas e/ou compromissos incompatíveis com os horários de uso ("Quando saio, às vezes esqueço de tomar"; "As reuniões da igreja acabam às 20h e eu chego em casa às $21 \mathrm{~h}$ ”); uso de substâncias psicoativas ("alcoolismo"); aspectos psicológicos associados à soropositividade ("Medo de perder os amigos por saberem que tenho HIV”; “As condições psicológicas, pois o Efavirenz e o Kaletra afetam a mente e até dificultam o trabalho"); precariedade sócio-econômica e da rede de apoio social ("Falta moradia e família"; "Fraqueza pela fome e sede"); ocorrência de outros estressores ("Estresse com a minha filha que é muito danada e não dorme direito"; "Problemas de saúde na família, minha mãe e filhos”).

\section{Análises bivariadas preliminares}

Foi investigada, preliminarmente, a associação entre adesão satisfatória e insatisfatória e variáveis sócio-demográficas, médico-clínicas e psicossociais, incluindo as variáveis preditoras e outras selecionadas pelos pesquisadores no intuito de agregar informação relevante ao tema adesão. Em relação a variáveis sócio-demográficas, os dois grupos não se diferenciaram quanto ao gênero, idade, situação conjugal e renda. Quanto à escolaridade, pessoas com nível educacional mais alto estiveram em maior freqüência entre as aderentes, alcançando significância estatística (Tabela 1).

Em relação a variáveis clínicas (Tabela 2), constatou-se diferença significativa quanto à interrupção da TARV por conta própria, com maior concentração de pessoas aderentes entre as que negaram interrupção anterior. Não se verificaram diferenças entre as condutas de adesão e as variáveis condição clínica, presença de efeitos colaterais, percepção da condição de saúde atual e tempo de diagnóstico de soropositividade.

Tabela 1

Associação entre variáveis sócio-demográficas e adesão à terapia anti-retroviral satisfatória ou insatisfatória.

\begin{tabular}{|c|c|c|c|c|c|c|c|}
\hline \multirow[t]{2}{*}{ Variáveis } & \multicolumn{2}{|c|}{ Adesão $<95 \%(n=28)$} & \multicolumn{2}{|c|}{ Adesão $\geq 95 \%(n=73)$} & \multicolumn{2}{|c|}{ Total $(N=101)$} & \multirow[t]{2}{*}{$\chi^{2}$} \\
\hline & $\mathrm{n}$ & $\%$ & $\mathrm{n}$ & $\%$ & $\mathrm{n}$ & $\%$ & \\
\hline Gênero & & & & & & & $d f=1$ \\
\hline Masculino & 18 & 29,5 & 43 & 70,5 & 61 & 60,4 & 0,24 \\
\hline Feminino & 10 & 25,0 & 30 & 75,0 & 40 & 39,6 & \\
\hline Escolaridade & & & & & & & $d f=1$ \\
\hline$\leq$ ensino médio incompleto & 23 & 37,7 & 38 & 62,3 & 61 & 100,0 & 7,66 * \\
\hline$\geq$ ensino médio completo & 5 & 12,5 & 35 & 87,5 & 40 & 100,0 & \\
\hline Idade (anos) ** & & & & & & & $d f=1$ \\
\hline$\leq 38$ & 17 & 32,1 & 36 & 67,9 & 53 & 100,0 & 1,05 \\
\hline$\geq 39$ & 11 & 22,9 & 37 & 77,1 & 48 & 100,0 & \\
\hline Situação conjugal & & & & & & & $d f=1$ \\
\hline Vive sem parceiro(a) & 8 & 21,1 & 30 & 78,9 & 38 & 100,0 & 1,35 \\
\hline Vive com parceiro(a) & 20 & 31,7 & 43 & 68,3 & 63 & 100,0 & \\
\hline Renda familiar (salário mínimo) & & & & & & & $d f=2$ \\
\hline $1-2$ & 18 & 30,5 & 41 & 69,5 & 59 & 100,0 & 1,59 \\
\hline $3-5$ & 6 & 31,6 & 13 & 68,4 & 19 & 100,0 & \\
\hline$>6$ & 4 & 17,4 & 19 & 82,6 & 23 & 100,0 & \\
\hline
\end{tabular}

* $\mathrm{p} \leq 0,001$.

** Divisão em dois grupos a partir da idade média da amostra. 
Associação entre variáveis clínicas e adesão à terapia anti-retroviral (TARV) satisfatória ou insatisfatória.

\begin{tabular}{|c|c|c|c|c|c|c|c|}
\hline \multirow[t]{2}{*}{ Variáveis } & \multicolumn{2}{|c|}{ Adesão < 95\% $(n=28)$} & \multicolumn{2}{|c|}{ Adesão $\geq 95 \%(n=73)$} & \multicolumn{2}{|c|}{ Total $(\mathbf{N}=101)$} & \multirow[t]{2}{*}{$\chi^{2}$} \\
\hline & $\mathrm{n}$ & $\%$ & $\mathrm{n}$ & $\%$ & $\mathrm{n}$ & $\%$ & \\
\hline Condição clínica & & & & & & & $d f=1$ \\
\hline Assintomático & 4 & 14,9 & 23 & 85,1 & 27 & 100,0 & 4,07 \\
\hline Sintomático & 25 & 33,8 & 49 & 66,2 & 74 & 100,0 & \\
\hline Efeitos colaterais & & & & & & & $d f=1$ \\
\hline Não & 15 & 24,2 & 47 & 75,8 & 62 & 100,0 & 0,99 \\
\hline Sim & 13 & 33,3 & 26 & 66,7 & 39 & 100,0 & \\
\hline Interrupção anterior da TARV & & & & & & & $d f=1$ \\
\hline Não & 4 & 7,4 & 50 & 92,6 & 54 & 100,0 & 23,90 * \\
\hline $\operatorname{Sim}$ & 24 & 51,1 & 23 & 48,9 & 47 & 100,0 & \\
\hline \multicolumn{8}{|l|}{ Tempo de diagnóstico de } \\
\hline soropositividade (anos) & & & & & & & $d f=3$ \\
\hline$<1-2$ & 4 & 16,0 & 21 & 84,0 & 25 & 100,0 & 3,13 \\
\hline $3-5$ & 7 & 25,9 & 20 & 74,1 & 27 & 100,0 & \\
\hline $6-9$ & 13 & 36,1 & 23 & 63,9 & 36 & 100,0 & \\
\hline$\geq 10$ & 6 & 31,6 & 13 & 68,4 & 19 & 100,0 & \\
\hline \multicolumn{3}{|c|}{ Percepção sobre a condição de saúde atual } & & & & & $\mathrm{df}=2$ \\
\hline Muito boa/Boa & 14 & 22,6 & 48 & 77,4 & 62 & 100,0 & 5,70 \\
\hline Regular & 13 & 43,3 & 17 & 56,7 & 30 & 100,0 & \\
\hline Ruim/Muito ruim & 1 & 11,1 & 8 & 88,9 & 9 & 100,0 & \\
\hline
\end{tabular}

${ }^{*} p \leq 0,001$.

Quanto às variáveis psicossociais, observou-se que os escores médios das pessoas com adesão igual ou maior que 95\% foram significativamente mais elevados nas variáveis autoestima, expectativa de auto-eficácia e suporte social (Tabela 3). Por outro lado, pessoas com adesão satisfatória obtiveram escores mais baixos em enfrentamento focalizado na emoção, sugerindo menor utilização de comportamentos evitativos, negação e emoções negativas para lidar com a soropositividade. Não se constataram diferenças estatisticamente significativas entre os escores médios das demais variáveis psicossociais.

\section{Preditores da adesão}

As variáveis preditoras (três dicotômicas e oito contínuas) foram incluídas na regressão logística padrão, independentemente dos níveis de significância obtidos nas análises bivariadas preliminares. O teste que comparou o modelo mínimo (a constante) com o modelo completo (constante e preditores) mostrou uma diferença estatística significativa $\left(\chi^{2}=51,50 ; \mathrm{df}=11\right.$; $\mathrm{p}<0,001)$. Outro modo de avaliar o ajuste do modelo consiste na comparação das predições com os resultados realmente observados. Observou-se que $93,2 \%$ das pessoas que apresentavam adesão satisfatória foram corretamente classificadas, ao lado de $71,4 \%$ das que estavam com adesão insatisfatória, com um acerto global da ordem de $87,1 \%$.

As variáveis interrupção anterior da TARV por conta própria $(\mathrm{p}<0,001)$ e expectativa de auto-eficácia $(\mathrm{p}<0,05)$ foram preditores significativos incluídos no modelo final. Escolaridade $(p=0,05)$ e suporte social $(p=0,06)$ alcançaram valores limítrofes de $\mathrm{p}$, com significância um pouco abaixo dos índices aceitáveis. As demais variáveis não apresentaram significância estatística, sem contribuição para o modelo final (Tabela 4). Assim, as chances de uma pessoa que não interrompeu anteriormente o tratamento por conta própria aderir à TARV é 14 vezes maior em comparação a uma que já interrompeu (OR = 14,87; 3,30-66,90); o acréscimo em uma unidade no escore da medida de auto-eficácia aumenta em quase 7 vezes a chance de adesão à TARV (OR = 6,95; 1,40-34,58).

Os índices Cox-Snell e Nagelkerke mostraram que o percentual de variância explicada da variável adesão ao tratamento no modelo final foi da ordem de $40 \%$ e $58 \%$, respectivamente. 
Escores médios das variáveis psicossociais em pessoas com adesão satisfatória e insatisfatória à terapia anti-retroviral ( $\mathrm{N}=101)$.

\begin{tabular}{|c|c|c|c|c|c|}
\hline \multirow[t]{2}{*}{ Variáveis } & \multicolumn{2}{|c|}{ Adesão $<95 \%(n=28)$} & \multicolumn{2}{|c|}{ Adesão $\geq 95 \%(n=73)$} & \multirow[t]{2}{*}{ t } \\
\hline & M & DP & M & DP & \\
\hline Auto-estima & 3,04 & 0,36 & 3,29 & 0,45 & $-2,67 *$ \\
\hline Auto-eficácia & 3,20 & 0,70 & 3,74 & 0,32 & $-3,90 * *$ \\
\hline Suporte social & 3,32 & 0,87 & 3,82 & 0,72 & $-3,01^{*}$ \\
\hline Enfrentamento focalizado no problema & 3,95 & 0,61 & 3,96 & 0,58 & $-0,09$ \\
\hline Enfrentamento focalizado na emoção & 2,78 & 0,67 & 2,34 & 0,75 & 2,60 * \\
\hline Busca de práticas religiosas/pensamento fantasioso & 3,82 & 0,89 & 3,89 & 0,73 & $-0,41$ \\
\hline Busca de suporte social & 2,90 & 0,90 & 3,00 & 0,92 & $-0,52$ \\
\hline Relação profissional de saúde-usuário & 4,01 & 0,67 & 4,27 & 0,74 & $-1,16$ \\
\hline
\end{tabular}

$* p \leq 0,01$

${ }^{\star *} p \leq 0,001$.

Tabela 4

Regressão logística da variável adesão à terapia anti-retroviral (TARV) como função de variáveis sócio-demográficas, clínicas e psicossociais $(\mathrm{N}=101)$.

\begin{tabular}{|c|c|c|c|c|}
\hline Variáveis & B & $\mathrm{p}$ & Razão odds & IC95\% \\
\hline Escolaridade ( 1 = baixa; 2 = alta $)$ & $-1,55$ & 0,05 & 0,21 & $0,04-1,00$ \\
\hline Efeitos colaterais ( 0 = não; $1=\operatorname{sim})$ & 1,16 & 0,12 & 3,20 & $0,73-14,02$ \\
\hline Interrupção anterior da TARV (0 = não; $1=\operatorname{sim})$ & 2,70 & 0,000 & 14,87 & $3,30-66,90$ \\
\hline Auto-estima & 0,48 & 0,61 & 1,62 & $0,25-10,28$ \\
\hline Auto-eficácia & 1,94 & 0,02 & 6,95 & $1,40-34,58$ \\
\hline Suporte social & 0,83 & 0,06 & 2,30 & $0,96-5,42$ \\
\hline Enfrentamento focalizado no problema & $-1,31$ & 0,08 & 0,27 & $0,06-1,18$ \\
\hline Enfrentamento focalizado na emoção & 0,51 & 0,40 & 1,66 & $0,50-5,48$ \\
\hline Busca de práticas religiosas/pensamento fantasioso & 0,59 & 0,21 & 1,76 & $0,72-4,54$ \\
\hline Busca de suporte social & $-0,06$ & 0,88 & 0,94 & $0,40-2,17$ \\
\hline Relação profissional de saúde-usuário & 0,16 & 0,70 & 1,18 & $0,51-2,71$ \\
\hline Constante & $-9,88$ & 0,03 & 0,00 & - \\
\hline
\end{tabular}

\section{Discussão}

A existência de uma política pública de acesso universal à medicação anti-retroviral em nosso país faz com que estudos sobre adesão à TARV sejam de grande relevância, para propiciar melhor compreensão do problema e atuação adequada das equipes profissionais, visando garantir boas condições de saúde e qualidade de vida a pessoas vivendo com HIV/AIDS.

A amostra do estudo apresentou características sócio-demográficas compatíveis com as tendências epidemiológicas nacionais, tais como a razão de casos homem/mulher (2 para 1), faixa etária com grande amplitude e predomínio de pessoas com baixa escolaridade e renda. A prevalência da adesão adequada à TARV encontrada foi semelhante à observada em outros estudos brasileiros 18,20. Apesar da identificação de bons indicadores para muitos dos participantes - níveis imunológicos e virológicos satisfatórios, percepção de boas condições de saúde e ausência de queixas sobre efeitos colaterais -, quase um terço dos pacientes apresentava adesão insatisfatória, permitindo concluir que o alcance de níveis adequados de adesão é um desafio para grande parte das pessoas soropositivas em tratamento.

Os resultados da pesquisa apontaram a necessidade de maior atenção das equipes para a 
presença de condições de vida e/ou de situações vivenciadas pelos pacientes (ainda que transitórias) que possam aumentar a vulnerabilidade para rupturas na adesão. O mais forte preditor - interrupção anterior da TARV por conta própria - é uma variável comportamental que pode ser determinada por contextos permanentes ou pontuais. Em outras palavras, os resultados sugerem que pessoas com história de falhas anteriores no uso da TARV talvez apresentem maior probabilidade de interromper novamente ou aderir em níveis insatisfatórios. O estudo contribuiu para apontar algumas das condições e/ou situações que podem constituir-se em risco para a não-adesão e que afetavam os participantes.

Quanto à expectativa de auto-eficácia, os resultados também foram ao encontro de outras pesquisas que constataram associação entre essa variável e o comportamento de adesão ${ }^{13}$. Assim, pessoas com maior expectativa de auto-eficácia em relação ao tratamento para o HIV/AIDS parecem aderir melhor aos esquemas terapêuticos. Ao contrário, aquelas que se percebem incapazes ou sem habilidades para manejar e/ou lidar com dificuldades eventuais oriundas do tratamento, parecem ter piores chances de aderir. A escala para medir essa variável foi válida para identificar as situações que podem representar riscos de rupturas na adesão. A incorporação de tais instrumentos no cotidiano das práticas e serviços de saúde pode ser uma estratégia eficaz para agregar informação e complementar a escuta individualizada sobre situações que aumentem a vulnerabilidade e os riscos de não-adesão. Ademais, reitera-se que a expectativa de autoeficácia pode ser trabalhada e modificada, pois ela se consolida em crenças, conhecimentos e comportamentos de saúde também passíveis de mudanças.

Os achados relativos à associação entre menor escolaridade e adesão insatisfatória, mesmo com valores limítrofes quanto à significância na análise multivariada, corroboraram resultados de outras pesquisas ${ }^{13}$. É possível supor que pessoas com poucos anos de estudo tenham menos acesso à informação sobre a enfermidade e o tratamento, acarretando compreensão insuficiente sobre o papel dos ARV e os prejuízos potenciais da não-adesão. Ademais, a escolaridade, comumente associada a níveis de renda, é um indicador indireto da situação sócio-econômica. Em suma, pessoas HIV+ com menor escolaridade podem estar vivenciando piores condições de vida e presença de outros estressores, além daqueles relativos à vivência da soropositividade, com impacto negativo sobre o autocuidado e a adesão ao tratamento.
Os resultados referentes ao suporte social também merecem comentários. Apesar de ter alcançado níveis insuficientes de significância na regressão logística, verificou-se nas análises bivariadas que pessoas com adesão satisfatória percebiam mais disponibilidade e estavam mais satisfeitas com o suporte social. O suporte social tem um papel importante ao amenizar conseqüências negativas de eventos estressantes, enquanto o apoio insuficiente de pessoas do meio sócio-familiar ou comunitário parece afetar negativamente a adesão, podendo ainda levar à depressão e à desesperança 27 . Diferentemente de outras enfermidades crônicas, muitas vezes os pacientes HIV+ optam por guardar segredo e manter sigilo sobre o seu diagnóstico, o que pode levá-los ao afastamento de pessoas que eventualmente poderiam prover apoio. Ademais, a vivência do preconceito (ou o medo de ser vítima de preconceito) pode ocasionar isolamento social e restrição dos relacionamentos interpessoais, com impacto negativo na estruturação da rede de suporte social de pessoas que vivem com HIV/AIDS $24,25,27,28$. Os profissionais de saúde devem estar atentos a esses aspectos, disponibilizando escuta e respeitando as escolhas dos pacientes, para auxiliá-los a consolidar apoios sociais consistentes e positivos, que contribuam para a qualidade de vida e a adesão ao tratamento.

A análise qualitativa agregou informação relevante aos demais resultados, permitindo a identificação de barreiras e situações adversas que parecem comprometer a adesão adequada à TARV. Algumas delas vão ao encontro de achados da literatura 9,12,15, que destacam a complexidade do tratamento anti-retroviral e as dificuldades que podem afetar a adesão: presença de efeitos colaterais, esquecimento, uso de substâncias psicoativas, incompatibilidade entre o tratamento e as rotinas de vida. Estratégias e intervenções diversas podem ser implementadas visando auxiliar o usuário a manejar, lidar, e mesmo superar, suas dificuldades 15,16. É fundamental que os profissionais adotem uma postura de acolhimento, favorecedora da escuta sobre as dificuldades do paciente, contribuindo para a sua vinculação ao serviço e à equipe de saúde.

Como limitações do estudo, merece destaque o fato de a amostra ter sido de conveniência, não permitindo que os resultados sejam generalizados. Outra limitação refere-se à utilização apenas de informações oriundas de auto-relato sobre o esquema terapêutico prescrito. Pode-se aventar a possibilidade de erros nessas informações, cuja fonte de dados mais fidedigna teria sido o próprio prontuário dos participantes. Recomenda-se, em 
estudos futuros, o confronto do auto-relato com registros sobre a conduta de adesão nos prontuários. Outra sugestão se refere à consideração da informação sobre o atraso na ingestão dos ARV para a definição dos casos de adesão satisfatória e insatisfatória. Tal questão coloca, no entanto, desafios quanto aos critérios para delimitação do intervalo de tempo e da freqüência de atrasos que poderiam caracterizar conduta de adesão adequada ou não.
Finalmente, é necessário reiterar que, pelo fato de a AIDS ser uma enfermidade crônica ainda estigmatizante, as questões de natureza psicossocial são de grande relevância, somando-se aos desafios da esfera biomédica. A constituição de equipes interdisciplinares parece ser de fundamental importância para a qualificação da assistência prestada, facilitando a abordagem adequada às dificuldades médicas e psicossociais de adesão à TARV em pessoas vivendo com HIV/AIDS

\section{Resumo}

O estudo objetivou descrever o comportamento de adesão ao tratamento anti-retroviral em pessoas vivendo com HIVIAIDS e investigar preditores da adesão entre as variáveis escolaridade, presença de efeitos colaterais, interrupção anterior da terapia anti-retroviral (TARV) por conta própria, auto-estima, expectativa de auto-eficácia, estratégias de enfrentamento, suporte social e satisfação com a relação profissional de saúde-usuário. Adesão foi medida pelo auto-relato da perda do número de comprimidos/cápsulas dos medicamentos anti-retrovirais na última semana e mês, sendo considerada satisfatória na ocorrência de omissão inferior a 5\% do total prescrito. Participaram 101 pessoas, $60,4 \%$ homens, idades entre 20 a 71 anos ( $M=37,9$ anos), 73,3\% sintomáticos. A coleta de dados incluiu entrevista e instrumentos auto-aplicáveis. A maioria ( $n=73 ; 72,3 \%$ ) relatou adesão igual ou superior a 95\%. Nos resultados da regressão logística, interrupção anterior da TARV e expectativa de auto-eficácia foram preditores significativos da adesão. Faz-se necessária a qualificação da assistência pela constituição de equipes interdisciplinares, para o desenvolvimento de abordagens adequadas às dificuldades médicas e psicossociais de adesão das pessoas vivendo com HIVIAIDS.

Terapia Anti-retroviral de Alta Atividade; Síndrome de Imunodeficiência Adquirida; HIV

\section{Colaboradores}

E. M. F. Seidl elaborou o projeto e coordenou a pesquisa, com destaque para a análise de dados e redação final A. Melchíades e V. Farias participaram da revisão da literatura, da coleta e análise de dados e da redação final. A. Brito participou da coleta e análise de dados, colaborando ainda na redação do texto. 


\section{Referências}

1. Baer M, Roberts J. Complex HIV treatment regimens and patient quality of life. Can Psychol 2002; 43:115-21.

2. Guarinieri M. Highly active antiretroviral therapy adherence: the patient's point of view. J Acquir Immune Defic Syndr 2002; 31:167-9.

3. Wu AW, Ammassari A, Antinori A. Adherence to antiretroviral therapy: where are we, and where do we go from here? J Acquir Immune Defic Syndr 2002; 31:95-7.

4. Vázquez IA, Rodríguez CF, Álvarez MP. Manual de psicología de la salud. Madrid: Ediciones Pirámide; 1998.

5. Paterson DL, Swindells S, Mohr J, Brester M, Vergis R, Squier C, et al. Adherence to protease inhibitor therapy and outcomes in patients with HIV infection. Ann Int Med 2000; 133:21-30.

6. Scalera A, Bayoumi AM, Oh P, Risebrough N, Shear $\mathrm{N}$, Tseng AL. Clinical and economic implications of non-adherence to HAART in HIV infection. Disease Management and Health Outcomes 2002; 10:85-91.

7. Ammassari A, Antinori A, Cozzi-Lepri A, Trotta MP, Nasti G, Ridolfo A, et al. Relationship between HAART adherence and adipose tissue alterations. J Acquir Immune Defic Syndr 2002; 31 Suppl 3: S140-4.

8. Singh N, Berman SM, Swindells S, Justis JC, Mohr JA, Squier C, et al. Adherence of Human Immunodeficiency Virus-infected patients to antiretroviral therapy. Clin Infect Dis 1999; 29:824-30.

9. Leite JCC, Drachler ML, Centeno MO, Pinheiro CAT, Silveira VL. Desenvolvimento de uma escala de auto-eficácia para adesão a tratamento anti-retroviral. Psicol Reflex Crít 2002; 15:121-31.

10. Bandura A. Self-efficacy: toward a unifying theory of behavioral change. Psychol Rev 1977; 84:191215.

11. Bandura A. Self-efficacy. In: Ramachaudran VS, editor. Encyclopedia of human behavior. New York: Academic Press; 1994. p. 71-81.

12. Catz SL, Kelly JA, Bogart LM, Benotsch EG, Auliffe TL. Patterns, correlates, and barriers to medication adherence among persons prescribed new treatments for HIV disease. Health Psychol 2000; 19:124-33.

13. Pinheiro CAT, Leite JCC, Drachler ML, Silveira VL. Factors associated with adherence to antiretroviral therapy in HIV/AIDS patients: a cross-sectional study in Southern Brazil. Braz J Med Biol Res 2002; 35:1172-81.

14. Gonçalves SCM. Comportamentos preventivos do câncer de mama e suas relações com variáveis psicossociais: um modelo estrutural [Tese de Doutorado]. Brasília: Universidade de Brasília; 2003.

15. Bartlett JA. Addressing the challenges of adherence. J Acquir Immune Defic Syndr 2002; 29 Suppl 1:S2-10.
16. Gavin LA, Wamboldr MZ, Sorokin N, Levy SY, Wamboldt FS. Treatment alliance and its association with family functioning, adherence, and medical outcome in adolescents with severe chronic asthma. J Pediatric Psychol 1999; 24:3555-65.

17. Paiva V, Leme B, Nigro R, Caraciolo J. Lidando com a adesão - a experiência de profissionais e ativistas na cidade de São Paulo. In: Teixeira P, Paiva V Shimma E, organizadores. Tá difícil de engolir? Experiências de adesão ao tratamento anti-retroviral em São Paulo. São Paulo: Núcleo de Estudos para Prevenção da AIDS, Universidade de São Paulo; 2000. p. 27-78.

18. Carvalho CV, Duarte DB, Hamann EM, Bicudo E, Laguardia J. Determinantes da aderência à terapia anti-retroviral combinada em Brasília, Distrito Federal, Brasil, 1999-2000. Cad Saúde Pública 2003; 19:593-604.

19. Seidl EMF. Pessoas vivendo com HIV/AIDS: configurando relações entre enfrentamento, suporte social e qualidade de vida [Tese de Doutorado]. Brasília: Universidade de Brasília; 2001.

20. Scaff IC. Adesão de pacientes HIV-soropositivos aos anti-retrovirais: inquérito epidemiológico em Cuiabá [Dissertação de Mestrado]. Cuiabá: Universidade Federal do Mato Grosso; 2002.

21. Martini M, D'Elia S, Paoletti F, Cargnel A, Adriani B, Carosi G, et al. Adherence to HIV treatment: results from a 1-year follow-up study. HIV Med 2002; 3:624.

22. Schönnensson LN, Ross MW, Williams M. The HIV medication self-reported nonadherence reasons (SNAR) index and its underlying psychological dimensions. AIDS Behav 2004; 8:93-101.

23. Seidl EMF, Tróccoli BT, Zannon CMLC. Análise fatorial de uma medida de estratégias de enfrentamento. Psicol Teor Pesqui 2001; 17:225-34.

24. Seidl EMF, Tróccoli BT. Desenvolvimento de escala para avaliação do suporte social em HIV/AIDS. Psic Teor Pesqui 2006; 22:317-26.

25. Renwick R, Halpen T, Rudman D, Friedland J. Description and validation of a measure of received support specific to HIV. Psychol Rep 1999; 84:66373.

26. Tabachnick GB, Fidell LS. Using multivariate statistics. New York: HarperCollins; 1996.

27. Schmitz MF, Crystal S. Social relations, coping, and psychological distress among persons with HIV/ AIDS. J Appl Soc Psychol 2000; 30:665-85.

28. Seidl EMF, Zannon CMLC, Tróccoli BT. Pessoas vivendo com HIV/AIDS: enfrentamento, suporte social e qualidade de vida. Psicol Reflex Crít 2005; 18:188-95

Recebido em 16/Fev/2006

Versão final reapresentada em 02/Jan/2007 Aprovado em 19/Abr/2007 